\title{
ARTICLES \\ International Perspectives on Online Dispute Resolution in the E-Commerce Landscape
}

\author{
Teresa Ballesteros*
}

\begin{abstract}
This article will examine Online Dispute Resolution (ODR) from several perspectives to provide a comprehensive understanding of the global efforts to incorporate $O D R$ in the e-commerce scope. Upon examining the nature and growth of both e-commercial activities and $O D R$, there will be an analysis from an international standpoint, where the article will discuss the relevant bodies and the progression of uniform standards in this regard. This is followed by an analysis of several jurisdictions, namely the United States, China, European Union and Australia. Finally, the essay will provide suggestions andrecommendations for the implementation of $O D R$.
\end{abstract}

Keywords: online dispute resolution (ODR), e-commerce, international dispute resolution, international law, United States, China, European Union, Australia, alternative dispute resolution (ADR), online platforms.

Trust is the concept behind the development of economic relations in any society. In unsophisticated forms of societal organizations, commercial relations occur mostly among neighbours, partners and acquaintances. For the economy to grow and commercial relations to expand, it is necessary to develop a legal infrastructure acting as a 'safety net' to establish the standard applicable conditions and the relevant forums to resolve disputes. These forums for dispute resolution are structured on the basis of societal needs. Traditionally, litigation was the avenue most synonymous with dispute resolution. However, a growing perception among the general public that the judicial system was costly, impersonal, slow and intricate shed light on the various disadvantages of litigious procedures. The situation was exacerbated by the expansion of trade and cross-border commerce. Besides, it was necessary to filter the flow of cases in order to prevent the collapse of the judicial system by small-claims disputes. Thus, alternative dispute resolution (ADR) was developed to address the gaps in dispute resolution that litigation uncovered. ADR has reached a position whereby it is recognized as a viable alternative to litigation and judicial processes.

* Teresa Ballesteros is a BCom/LLB student at the University of Sydney. 
Online dispute resolution (ODR) originally branched out from ADR as a natural by-product of the inception of cyberspace; however, it has become an independent entity in recent years due to a growth in ODR pursuits. In summary, ODR involves settling disputes wholly or partly with the assistance of electronic or digital tools. These tools range from web-based communication platforms connecting the relevant parties to artificial intelligence (AI) replacing the role of traditional mediation and arbitration officers. The use of ODR extends from online and web-based disputes to claims stemming from 'offline' dealings. The online aspect does not reflect the origins of the claim; instead, it conceptualizes the procedural nature of the resolution itself.

Since the beginning of the Internet boom, much of the legal literature on ODR has ascertained the imminence of the integration of virtual processes into the legal sphere. ${ }^{1}$ In 1998, Smedinghoff and Bro identified that e-commerce disputes are substantially different from offline disputes and therefore require means suitably adapted for the resolution thereof. ${ }^{2}$ In 2003, Lodder and Bol highlighted the two distinct angles of this interconnection: the legal implications of information technology (IT) and the relation between AI and law. They reached the conclusion that "technically oriented people and legally oriented people should jointly work on the development of an ODR environment". ${ }^{3}$

In recent years, ODR has revolutionized the judicial scope across a variety of jurisdictions, with the most adapted area of ODR implementation occurring in e-commerce disputes. Three main reasons can be found:

1 The explosive growth in global e-commerce transactions, from $\$ 1.55$ trillion in 2015 to almost $\$ 5$ trillion in sales in $2021 .{ }^{4}$ In turn, this translated into a surge in the e-commerce share of total global retail sales from $7.4 \%$ in 2015 to $18 \%$ in 2020. ${ }^{5}$ Digital buyers worldwide amounted to 2.050 billion in 2020, which represents $64.6 \%$ buyer penetration.

2 The strong commitment of both governments and e-commerce companies to continue supporting the healthy development of the e-commerce ecosystem, including the development of effective and agile dispute resolution mechanisms to guarantee the protection of rights and the enforcement of obligations by all parties involved.

3 Web-based mechanisms are the natural environment for digital natives who appreciate the convenience of click-based solutions. Besides, the nature of the disputes is most of the time simple, repetitive and small value, making the dispute resolution process rather straightforward.

1 C. Rule, 'Online Dispute Resolution and the Future of Justice', Annual Review of Law and Social Science, Vol. 16, No. 1, 2020.

2 T. J. Smedinghoff \& R. H. Bro, 'Moving with Change: Electronic Signature Legislation as a Vehicle for Advancing E-commerce', The John Marshall Journal of Computer and International Law, Vol. 17, No. 5, 1998, p. 723.

3 A. R. Lodder \& S. H. Bol, 'Towards an Online Negotiation Environment: Legal Principles, Technical Requirements and the Need for Close Cooperation', ADRJ Online Monthly, 2003.

4 S. Chevalier, 'Retail E-commerce Sales Worldwide from 2014 to 2024', Statista, (7 July 2021), www. statista.com/statistics/379046/worldwide-retail-e-commerce-sales/, accessed 24 August 2021.

5 Ibid. 
This article will first examine the attempts at the standardization of ODR in the e-commerce field on a global scale, and the lack of uniformity in the progression of virtual alternatives. Second, it will discuss the development of ODR in selected areas - the United States, China, the European Union (EU) and Australia. These jurisdictions are comparable in that they are highly receptive to digital innovation, and there are varying degrees of acceptance of ODR across these areas. All have welcomed e-commercial ODR in contrasting manners, and this article will evaluate each of their attempts.

The underlying conclusion is that the trajectory of ODR is not linear, and is not the same for all jurisdictions. Given the growth of electronic processes, and the impact of COVID-19 on the adaptations to digital innovations, ODR is inevitable. However, it is difficult to pinpoint a time frame for its implementation. In addition, it is crucial to clarify that ODR will not become the normative path for dispute resolution; it is an option along with litigation and ADR, and may not be appropriate in all dispute categories. An assessment of the eventual shortcomings or even the possibility that it may lead to new categories of problems is of great relevance and will also be discussed.

\section{International Level}

At the international level, ODR is progressively more necessary in an increasingly globalized world where e-commerce grows consistently at annual two-digit rates. As Katsh and Rifkin anticipated in 2001, litigation and conventional ADR cannot equate with the manner in which their digital counterparts save effort, time and costs. ${ }^{6}$ The repercussions of the COVID-19 pandemic in this field merely accelerated the inevitability of transitioning into the online world.

Irrespective of whether ODR is implemented at the international or domestic level, there are universal principles that must be adhered to. These standards encapsulate the inherent principles of dispute resolution: justice, fairness and neutrality. Since these beliefs are subject to individual interpretation, ${ }^{7}$ it is difficult to condense them into a cohesive set of universal standards. On top of this onerous task, ODR must uphold procedural fairness and ensure equity among the parties and across all outcomes. All of this must be underpinned by the aforementioned trust, in order to ensure that the relevant parties are comfortable in the process. ${ }^{8}$ There are an additional four elements to determine whether the parties have experienced procedural justice in a dispute resolution process: neutrality, voice, courte-

6 E. Katsh \& J. Rifkin, Online Dispute Resolution, Resolving Conflicts in Cyberspace, 1st edition, Wiley, San Francisco, 2001, p. 226.

7 F. Abedi, J. Zeleznikow \& C. Brien, 'Universal Standards for the Concept of Fairness in Online Dispute Resolution in b2c E-disputes', Ohio State Journal on Dispute Resolution, Vol. 34, No. 2, 2019, p. 361.

8 O. Turel \& Y. Yuan, 'Online Dispute Resolution Services: Justice, Concepts and Challenges', in Handbook of Group Decision and Negotiation, 2010, pp. 425-429. 
sy and respect. ${ }^{9}$ Neutrality is significant due to its correlation with the idea of fairness and equity. The notion of voice essentially determines the degree to which the parties feel they can express themselves and communicate openly. ${ }^{10}$ Courtesy and respect take a more interpersonal approach, and indicate the way in which parties treat one another. Furthermore, Schmitz emphasizes the need for equitable treatment and transparency, ${ }^{11}$ in order to gain the trust of the general public. These values resonate with the aforementioned four elements in that they reiterate the need for interpersonal relations to be monitored to ensure an impartial outcome. In 1998, the European Commission enumerated the seven principles applicable to extrajudicial (arbitration) consumer disputes: independence, transparency, respect of the adversarial principle, effectiveness, legality, liberty and representation. ${ }^{12}$ These principles can be extrapolated to apply to ODR.

The International ODR Forum is one of the main institutions that monitors the progress of ODR at a global scale. The annual forums have issued several recommendations and have generally permeated other regulatory bodies in the scope of ODR. The scope of the discussions expands from e-commerce activities to the social implications of ODR; these include ODR in sport, accessibility for persons with disabilities and social intuition for virtual processes. The forum also explores the technicalities and functionality, the role of AI in dispute resolution and the uncovered potential of ODR in high-stakes disputes. This space for dialogue on ODR has enabled experts in the field to pose suggestions for the amelioration of the current ODR situation, as well as analyse its progression.

Other pertinent documents for ODR development are those produced by the Organization for Economic Co-Operation and Development (OECD). It is a relevant international body in this field, being

(...) an international organisation in which governments work together to find solutions to common challenges, develop global standards, share experiences and identify best practices to promote better policies for better lives. ${ }^{13}$

It had issued the Guidelines for Consumer Protection in the Context of Electronic Commerce in $2000^{14}$ and the Recommendations on Consumer Dispute Resolution and Redress in 2007..$^{15}$ The Guidelines are foundational recommendations to foster better conduct by businesses. They propose a variety of dispute resolution mecha-

9 F. Abedi, J. Zeleznikow \& C. Brien, 'Universal Standards for the Concept of Fairness in Online Dispute Resolution in b2c E-disputes', Ohio State Journal on Dispute Resolution, Vol. 34, No. 2, 2019, p. 368.

10 J. Thibaut \& L. Walker, 'Procedural Justice: A Psychological Analysis', 1975, p. 12.

11 A. J. Schmitz, 'Building Trust in Ecommerce through Online Dispute Resolution', in J. A. Rothchild (Ed.), Research Handbook on Electronic Commerce Law, 2016, pp. 307, 328.

12 Commission Recommendation of 30 March 1998, OJ 1998 L 115/31.

13 OECD, 'Discover the OECD. Better Policies for Better Lives', www.oecd.org/general/Key-informationabout-the-OECD.pdf, accessed 18 August 2021.

14 OECD, Guidelines for Consumer Protection in the Context of Electronic Commerce, OECD Publications Service, Paris, 2000.

15 OECD, Recommendations on Consumer Dispute Resolution and Redress, OECD Publications Service, Paris, 2007. 
nisms, and were implemented foreshadowing the booming e-commerce economy. They have served as the foundational pillars for future documents concerning ODR in e-commerce transactions. Similarly, the Recommendations closely resemble the Guidelines and provide a framework for addressing cross-border and domestic disputes in the scope of B2C transactions. With regard to the status of both initiatives, the Guidelines have been adopted by the member states of the OECD, whereas the Recommendations were embraced by members each at their own pace, in spite of the OECD's intention to mitigate the discrepancies between nations.

Another relevant body working at the international level is the United Nations Commission on International Trade Law (UNCITRAL). UNCITRAL is "the core legal body of the United Nations system in the field of international trade law". ${ }^{16}$ As a subsidiary of the UN, it has the advantage of a strong reputation and international credibility, and is responsible for international trade. In response to the surge in cross-border disputes arising from e-commerce transactions, UNCITRAL drafted a series of technical notes ${ }^{17}$ to reflect the ODR process. They were created to foster the development of ODR in cross-border disputes, specifically low-value sales or service contracts finalized through online communications. The technical notes delineate a set of principles that underpin ODR processes: fairness, transparency, due process and accountability. UNCITRAL also institutes a guide with stages of an ODR dispute settlement, and any minor or technical issues that arise from utilizing ODR-based platforms. In short, the UNCITRAL notes aimed to mitigate the issues arising from cross-border disputes, such as language barriers and any jurisdictional issues.

A final example of a key body in the implementation of ODR is the International Mediation Institute (IMI). IMI plays a pivotal role in engaging private bodies, such as law firms, in the discussion of ODR. It has also organized the Global Pound Conferences, a two-part series willing to shape the future of ADR. The conferences intended to mitigate issues in the resolution of civil and commercial disputes, and the ways to maximize the efficiency of online technologies. Unfortunately, they only ran for two sessions, but they were considered to be successful in congregating the relevant of stakeholders to speculate on the future of ADR.

The growing community of legal professionals with expertise in ODR considers Katsh and Rifkin's initial ideas on the matter as seminal. Katsh and Rifkin produced a three-step developmental chronology for the implementation of ODR within jurisdictions, which has been referred to greatly in legal discourse to measure the level of integration of ODR. The stages have been termed the 'hobbyist' phase, the 'experimental' phase and the 'entrepreneurial' phase. ${ }^{18}$ The 'hobbyist' phase is where individuals seek to develop ODR on an amateur level. The 'experimental' phase suggests that organizations begin trialing different forms of ODR through pilot programmes. The 'entrepreneurial' phase refers to private enterprises using ODR on a larger scale. A significant number of jurisdictions, including the

UNCITRAL webpage, “About” section, https://uncitral.un.org/en/about, accessed 3 August, 2021.

18 E. Katsh \& J. Rifkin, Online Dispute Resolution, Resolving Conflicts in Cyberspace, Wiley, San Francisco, 2001. 
four examined in this article, have entered the fourth phase - the 'institutional' phase - added by Conley, Tyler and Bretherton. ${ }^{19}$ As the term may illustrate, ODR has reached a stage of institutionalization, whereby official bodies are employing ODR in their resolution mechanisms. In essence, the jurisdictions discussed later in this article have reached the final stage of ODR implementation.

The growth of e-commerce has enabled the international bodies to reconsider the conventional assertions of dispute resolution, and create a malleable process that is adapted on a situational and contextual basis. Among these, the International Council for Online Dispute Resolution (ICODR) is working at establishing a set of global standards. ${ }^{20}$ It has a brief outline of the qualities necessary for ODR to be successful, which are the following: accessible, accountable, competent, confidential, equal, fair/impartial/neutral, legal, secure and transparent. The Asia Pacific Economic Co-operation (APEC) is in the process of developing a B2B dispute resolution system ${ }^{21}$ that will operate purely online and mirror the EU Regulation discussed later in this article. APEC will rely on national institutions to assist in the mediation and arbitration of the disputes, but will carry out the operations over the Internet. Overall, the primary objective of ODR is to engender a transparent and neutral ODR ecosystem in international disputes.

\section{Jurisdictions}

\subsection{United States}

In the United States, the growth of ODR occurred simultaneously with the expansion of the Internet. In a social and judicial context, ODR followed slowly and steadily, and has grown significantly. As of 2019, more than 50 county and statewide courts had been developed. ${ }^{22}$ The vast, expansive geography of the United States has facilitated the implementation of ODR; this has served to mitigate the access to justice for a larger section of the population, at a lower cost than traditional resolution methods and litigation. The United States has developed three major ODR platforms that have been introduced at a global scale. These are Modria, Cybersettle and SquareTrade.

Modria is a San Francisco-based platform, facilitating civil dispute resolutions in the commercial sector. It aims to provide access to ODR technologies to internal business disputes. Modria has extended its services to public agencies in the United States such as the American Arbitration Association (AAA), which has mitigated the problem of caseload management in New York. The platform manages more than 300,000 cases annually, specifically for the AAA. Other web-based platforms have integrated the modules created by Modria, making them one of the pioneers in the international ODR ambit.

21 https://www.apec.org/Meeting-Papers/Annual-Ministerial-Meetings/2017/2017_amm/Annex-A.

22 www.colinrule.com/writing/future.pdf. 
Cybersettle was created out of a need to settle claims quickly and economically. The web-based service offers high-speed settlements between parties by comparing their respective demands; if the offer is greater than or equal to the opposition, the claim settles instantly. The main purpose is for single-use monetary claims. ${ }^{23}$ Since its creation in 1996, Cybersettle has received a great amount of traction, and has assisted in almost 200,000 claims, representing $\$ 1,457,299,751$ in settlements, to date. ${ }^{24}$

Although SquareTrade is no longer in operation as an independent entity, its process served to mould the eBay ODR system into its present form. SquareTrade differed from the aforementioned platforms in that the parties could offer solutions, and if they did not come to a mutual agreement, SquareTrade offered e-mediation to the parties. Once a solution had been conceived, both parties signed an e- contract and were therefore bound to this. Currently, SquareTrade has transitioned into the eBay ODR platform, and is the dispute resolution provider.

Within the private sector, the two main domestic companies that have endeavoured to integrate ODR within their dispute resolution system are eBay and PayPal. These companies began their journey as a result of the growing demand for internal platforms that could identify and resolve consumer disputes smoothly.

First, the resolution process adapted in SquareTrade was replicated in the eBay dispute resolution portal. The operations undertaken under the eBay platform encompass such a wide variety of disputes that the resolution portal has seen incredible developments in the last few decades. eBay recognizes the importance of algorithms in dispute resolution, and their role in generating fast and economic decisions. In comparison to human mediation, algorithmic processes allow for a symmetric approach to dispute resolution, with no human error or bias permeating the equation. Additionally, the system incorporates computer-mediated communications, available to the buyers and sellers, as well as patent-pending technology. The process begins with the claimant filing a complaint through the SquareTrade portal. To do this, the claimant must register with a unique identification number and password, and enter the details of the claim. Through the computer-mediated communications, the parties can resolve the issue independently, with the process generally taking 10 days to finalize. eBay has penetrated the global scale in terms of recognition of ODR, and every year it handles over 60 million disputes. $^{25}$

PayPal differentiates itself through its dispute resolution process. The onus is on the seller to disprove the claim, by demonstrating fulfilment of duty. The process commences with the buyer filing a dispute, followed by PayPal pausing the transfer of funds between the parties. It is then the duty of the parties to coincide

23 A. R. Lodder \& J. Zeleznikow, 'Technologies for Supporting Dispute Resolution', in A. R. Lodder \& J. Zeleznikow (Eds.), Enhanced Dispute Resolution through the Use of Information Technology, Cambridge University Press, Cambridge, 2010, p. 76.

24 www.cybersettle.com/.

25 A. Pearlstein, B. Hanson \& N. Ebner, 'ODR in North America', in M. S. Abdel Wahab, E. Katsh \& D. Rainey (Eds.), Online Dispute Resolution: Theory and Practice: A Treatise on Technology and Dispute Resolution, Eleven International Publishing, The Netherlands, 2012, pp. 443-464. 
in a solution, and resolve their dispute within 20 days. ${ }^{26}$ If the dispute has not reached a conclusion, the dispute is escalated to a claim, and PayPal overtakes the investigation phase and determines the outcome. The platform has also imposed restrictions on the appeals process, to inhibit unnecessary appeals from claims.

The scope of ODR in the United States has proven to be limitless. At the private and public levels, online mechanisms for dispute settlement have been integrated gradually and now hold a reputable position in dispute resolution. There are incredible technological advancements occurring in the United States, and it is a matter of time for them to penetrate the dispute resolution arena for legal reform. Digital processes will be a force to be reckoned with, and they are not to be underestimated in the domestic legal landscape.

\subsection{China}

As the global leader and driving force in technology and e-commerce, China is a notable subject to examine in terms of its ODR development, and is commended as a pioneer in ODR advancements. With over 800 million Internet users, ${ }^{27}$ the $\mathrm{Chi}$ nese virtual landscape is incomparable with any other jurisdiction, and the need for digitization is aggressively overtaking the traditional mechanisms of dispute resolution. However, the development of ODR can be traced back to e-commerce platforms and the private sector. Within this area, there have been two significant attempts at introducing ODR: ODR platforms internalized in the e-commerce institution, and e-mediation supported by the national e-commerce industry. ${ }^{28}$

Before delving into the e-commerce sector, it is important to explore how the Chinese courts have supported, and encouraged, the beginning of a new era of technological reform. The Chinese judiciary has been radically transformed by e-processes, and there are currently three Internet Courts across the nation - in the major cities of Hangzhou (est. 2017), Beijing (est. 2018) and Guangzhou (est. 2018) - which had settled over 120,000 disputes as of 2019 , since their creation. ${ }^{29}$

The Hangzhou Internet Court focuses precisely on Internet disputes and e-commerce claims. It is the best-established court for e-mediation. The processes for the Hangzhou court are unique in that the disputants are required to undertake most of the mediation proceedings online. ${ }^{30}$ The mediation officer then contacts the parties over the phone or via online or video communications.

The Beijing Internet Court is very similar. The most remarkable aspect of the Beijing court is its inclination towards AI, and the shift away from in-person court processes. ODR experts have envisaged the use of $\mathrm{AI}$ in dispute resolution as a future prospect; yet, the Beijing judiciary has outdone the rest of the world as a lead-

www.paypal.com/us/webapps/mpp/security/resolve-disputes.

中国互联网络发展状况统计报告 (Annual Report on China's Internet Development, China Academy of Information and Technology Communications), White Paper, Vol. 20, No. 4, 2018, p. 1.

8 C. S. Shang \& W. Guo, 'The Rise of Online Dispute Resolution-led Justice in China: An Initial Look', Australian National University Journal of Law and Technology, Vol. 1, No. 2, 2020, pp. 25-42.

29 The Supreme People's Court of the People's Republic of China 五方面展示中国法院互联网司法 制度优势和治理能力 (Five Aspects of Progress in Chinese Internet Courts), White Paper, Vol. 73, No. 4, 2019.

30 NCTDR, 'Hangzhou Internet Court', NCTDR (18 August 2017), http://odr.info/hangzhou-internetcourt/, accessed 25 August 2021. 
er in this regard. The most outstanding feature has been the development of an AI judge as part of an online litigation centre, ${ }^{31}$ which will greatly reduce the need for physical attendance in court on behalf of the parties. The AI judge will be fundamental in completing menial, repetitive tasks, and has a female appearance and voice. The court has high hopes for this unique judge, and 'she' will be programmed on the basis of the latest innovations to engage in a question and answer scenario, and have cohesive communication with users.

Finally, the Guangzhou Internet Court mirrors the structure of the Hangzhou Internet Court, and has not yet caught up with the Beijing Internet Court. These three courts are regulated by a set of standards established by the Supreme People's Court of China called the 'Rules of Online Litigation of the People's Court of China (Rules)'. ${ }^{32}$ The Rules have been enacted, and entered into effect on $1 \mathrm{Au}$ gust 2021. As of this moment, there is insufficient evidence to verify the effectiveness of the Rules, and whether the courts have implemented them. Overall, ODR in Chinese judicial processes is flourishing, and there is no indication that this will slow down.

As noted by scholars, Chinese e-commerce platforms have been 'forced to create law', ${ }^{33}$ including on dispute resolution mechanisms, by delegation of the party-state. Two reasons may lie behind this situation. The first is the initial absence of a formal legislative framework and the need to incentivize the development of the e-commerce sector. The second is the convenience of utilizing the more experienced private sector in such risky initial ventures. ${ }^{34}$

As a consequence, e-commerce businesses have successfully integrated ODR into their complaint-processing systems. The Alibaba Group is the world's largest e-commerce ecosystem with a global consumer base exceeding 1 billion users in the fiscal year ending March 2021. ${ }^{35}$ Taobao, often regarded as the Chinese counterpart of eBay, and owned by the Alibaba Group, is distinguishable from other platforms as the world's largest $\mathrm{C} 2 \mathrm{C}$ e-commerce platform. Taobao has built a community of 10 million active sellers, and a growing 423 million active buyers. ${ }^{36}$ The self-contained ODR platform within Taobao was developed in accordance with the eBay ODR platform. The resolution process commences with a text-based negotiation programme. The consumer is presented with the option of submitting a claim against the seller, and Taobao ODR specialists have 10 days to conclusively decide whether to proceed with the claim or not. Aside from C2C disputes, Taobao enables brand owners to submit claims related to counterfeit products. These claims are mediated and adjudicated online with the assistance of a Taobao staff member, who personally analyses the claim to determine whether there is an issue of coun-

31 Liangyu, 'Beijing Internet Court Launches AI Judge', Xinhua Net (27 June 2019), www.xinhuanet. com/english/2019-06/27/c_138178826.htm, accessed 24 August 2021.

32 Rules of Online Litigation of the People's Court of China 2021 (Supreme People's Court of China).

33 'Taobao, Federalism, and the Emergence of Law, Chinese Style', Minnesota Law Review, Vol. 102, No. 1563, 2018, p. 1563.

34 L. Liu \& B. R. Weingast, 'Law Chinese Style: Solving the Authoritarian's Legal Dilemma through the Private Provision of Law'. Working Paper, August 2020.

35 https://alibabagroup.com/en/news/press_pdf/p210513.pdf.

36 L. Liu \& B. R. Weingast, 'Taobao, Federalism, and the Emergence of Law, Chinese Style', Minnesota Law Review, Vol. 102, No. 1563, 2018, p. 1583. 
terfeiting. ${ }^{37}$ Taobao also has a comparative advantage that proves to be an asset to its promise of fairness and transparency: it has introduced an adjudication system with a quasi-jury panel, namely, the Alibaba Public Jury. ${ }^{38}$ The overwhelming success of the ODR system within Taobao facilitated this to transcend other domestic platforms, such as WeChat and DiDi. Unfortunately, the success was not replicated across all e-commerce sites; ${ }^{39}$ however, this does not diminish the positive growth of ODR in China.

Second, the development of ODR at an industrial level is significant, as it paved the way for the e-commerce mediation platform Dian Su Bao. In essence, Dian Su $\mathrm{Bao}$ is an e-commerce consumer dispute mediation platform, and it provides an online portal for consumers to submit electronic complaints. It further assists in connecting official mediators to the case in order to ameliorate the resolution procedure. Dian Su Bao's uniqueness lies in its lack of affiliation to any commercial institution, as well as its feedback section for users to provide recommendations for increasing its user-friendliness and accessibility.

One of the primary hindrances to the development of ODR in any jurisdiction is the increased risk of data breaches and invasions of privacy. A federal survey conducted by Xinhua, the state-run media agency, elucidated the severity of poor data protection, and the general discontentment with the consumer protection measures. To quantify this issue, $85.2 \%$ of the respondents alleged they had been impacted by a leakage in their personal information and data. ${ }^{40}$ From this cohort, $80 \%$ of the respondents are dissatisfied with consumer protection and privacy. ${ }^{41}$

It is practically impossible to eradicate the possibility of issues regarding the security of information. However, the Chinese Ministry of Industry and Information Technology, China's Cyberspace Administration and the Ministry of Public Security and State Administration for Market Regulation have taken a step in the right direction. In 2019, they enacted the Guidelines on Determining Illegal and Illicit Collection and Use of Private Information by Applications. ${ }^{42}$ The Guidelines aim to reduce the illegal collection of personal information and data by applications, which may encompass ODR platforms. The purpose is to improve the standards of confidentiality in order to enhance the accessibility of ODR platforms.

Regardless of whether ODR is implemented at the private or public level, China has demonstrated the seamless nature of digital processes and has proved to be a pioneer in the realm of ODR. The innovation displayed by China serves an indication of the possibilities attributed to ODR. The backside of the case relates to the

39 解决1500万起纠纷, 腾讯滴滴都学习, 阿里首创这项机制成共识 (Tencent and Didi Both Learnt from Alibaba's Pioneering Dispute Resolution Mechanism), 2019.

40 Z. Qi, 'China Consumers Association: More than $80 \%$ of Respondents were Leaked by APP Personal Information', Xinhua Net (30 August 2018), para. 1, www.xinhuanet.com/fortune/201808/30/c_1123350774.htm, accessed 24 August 2021.

41 Ibid.

42 《Ap违法违规收集使用个人信息行为认定方法》 [Guidelines on Determining Illegal and Illicit Collection and Use of Private Information by Apps] (People's Republic of China) Cyberspace Administration of China, Ministry of Industry and Information Technology, Ministry of Public Security and State Administration for Market Regulation, 28 November 2019. 
potential for an increasing distrust in a dehumanized paralegal system excessively reliant on technology.

\section{$2.3 E U$}

The unique aspect about the EU is that its states are highly interconnected and prone to digitization. There are already uniform policies and regulations covering an array of different issues, including within the scope of e-commerce and online processes. Due to this, ODR has been well received, and the discourse has been largely positive. In particular, the EU is commended for having legislated a comprehensive tool for ODR within the ambit of e-commerce.

The EU Parliament has passed legislation on ODR for consumer disputes (the Regulation), specifically regarding the use of ODR for e-commerce purposes. This legislative enactment aims to promote consumer protection by developing a European ODR platform. In short, the objective is to "[facilitate] the independent, impartial, transparent, effective, fast and fair out-of-court resolution of disputes between consumers and traders online". ${ }^{43}$ In particular, the Regulation is concerned with contractual disputes arising from B2C e-commerce transactions between parties in different EU member states and involving the use of the ODR platform. ${ }^{44}$

The reference to the ODR platform emerges from Chapter II of the Regulation, whereby the EU Council will develop, design and maintain an ODR platform to meet its proposals. ${ }^{45}$ The Regulation highlights the functional aspects of the platform, which include, but are not limited to, the following: ${ }^{46}$

- To provide an electronic complaint form

- To inform the respondent party about the complaint

- To offer an electronic case management tool free of charge

- To provide a feedback system

Moreover, member states are required to delegate a contact point, who will provide supplementary support for the overall resolution of the dispute. ${ }^{47}$ The contact point may also have at least two advisers specializing in ODR. The Regulation also noted issues concerning the database, processing of personal data, data confidentiality and security, consumer information and the role of the competent authorities. ${ }^{48}$ The Regulation concludes with a list of relevant information to be provided when submitting a complaint, which includes, but is not limited to, the following:

- Name and location of the complainant

- Name, address and website of the trader

- The type of good or service to which the complaint relates

- The date on which the transaction was made

- Type and description of the complaint 
The binding nature of the Regulation purports to standardize the implementation of ODR across all member states, thereby validating attempts at universal standards of acceptance for ODR. Furthermore, the Regulation specifies for annual reports to the European Parliament and Council on the progress of ODR, ${ }^{49}$ its user-friendliness and shortcomings, along with proposals for adaptations. ${ }^{50}$ The EU ODR platform has been made public under the domain ec.europa.eu/consumers/ odr. The website appears in the official language of each member state, and has been developed to adhere to the accessibility standards that permeate the Regulation.

Furthermore, the EU has implemented a B2C dispute resolution portal, specifically for disputes arising out of e-purchases, ${ }^{51}$ which arises out of the Regulation. The benefits of this portal are the measures implemented to ensure accessibility irrespective of the claim. For example, the portal is available in all official EU languages, and offers free of charge dispute resolution. The process is conducted entirely online, and a competent dispute settlement body handles the dispute resolution process. The claimant bears the onus of informing the counterparty about the ODR platform. The website also aims to educate the public on EU Consumer Law, through a programme called Consumer Law Ready. This is particularly useful for smaller businesses, which may not have the legal resources available to larger enterprises. Within this course, businesses learn more about the possible avenues of dispute resolution, and are introduced to ODR.

The Network for European Consumer Centres (ECC) has a significant amount of experience in handling cross-border disputes in the commercial sector. The primary objective of the ECC is to promote and ensure consumer protection standards are maintained across all EU countries, and foster an ambiance of trust with respect to $\mathrm{B} 2 \mathrm{C}$ transactions. The ECC utilizes online mechanisms to provide assistance and help, free of charge, for any party experiencing issues in cross-border commercial dealings. It does not explicitly engage in ODR activities, but utilizes the online environment to assist consumers and businesses in their resolution of disputes. There is also an acknowledgement of ADR mechanisms as viable alternatives to court proceedings, and it is possible that the ECC has been involved in ODR within this scope. In short, the assimilation of ADR into the dispute resolution procedures of the Network for ECC will certainly pave the way for its online counterpart to be utilized in the future.

In this respect, the EU has pioneered in the ambit of platform to business (P2B) by legislating a tool aimed at protecting small and medium-sized enterprises (SMEs) that operate on online platforms. ${ }^{52}$ This Regulation targets - in order to promote fairness and transparency for business users - certain unfair practices by online platforms that provide commercial intermediation services. In particular, the legislation introduces mechanisms of redress for businesses in order to level the playing field between Internet giants and third-party sellers. Among the target-

https://europa.eu/youreurope/business/dealing-with-customers/solving-disputes/online-disputeresolution/index_en.htm.

Council Regulation 2019/1150, OJ 2019 L 186/57. 
ed practices are the unilateral changes to online terms, insufficient transparency of the online ranking conditions and inadequate internal complaint-handling mechanisms.

The nature of the EU has facilitated the reform of traditional dispute resolution mechanisms, both at the national and supranational levels. In turn, this has enabled e-processes to gradually manoeuvre their way into resolution procedures. The success of the ODR integration is attributed to the interconnectedness of the nations within the EU, and their pre-established legislative bodies that allowed for uniformity across all areas. The EU is exemplary in showcasing the possibilities of ODR, and the potential for homogeneity in cross-border disputes, and therefore at the global scale. Additionally, the EU has addressed e-commerce disputes from the perspectives of consumers and businesses, in particular small businesses. This has been instrumental in ensuring that they receive equitable treatment in dispute resolution proceedings.

\subsection{Australia}

Over the last decades, Australia has fostered a sustainable environment for ADR. Courts and tribunals in Australia now have the power to refer disputes to ADR processes, and ADR is regarded as a viable prerequisite to litigation processes. ${ }^{53}$ Similarly, ODR has evolved successfully, albeit gradually, within the legal sphere. The Australian Dispute Resolution Advisory Council (ADRAC) is the primary body examining the development of ODR in Australia. Although Australia has reached an advanced stage of ODR development as per international standards, ADRAC recognizes that this progress did not fulfil the preconceived anticipation. ${ }^{54}$ Australia has a unique combination of features, including geographical remoteness and an open-minded population; these variables had the potential to catalyse legal reform in the ODR field. However, Australia has been reticent about a digital revolution in the legal sector. ${ }^{55}$ This may be attributed to the dehumanization behind online processes, as well as the complexity perceived by users. ${ }^{56}$ However, the Federal Court of Australia recently suggested that domestic courts are beginning to embrace online trials, ${ }^{57}$ which is a notable turning point in ODR reform for the judiciary.

There are no instruments that introduce ODR-friendly legislation; however, there are laws related to e-commerce that incorporate the principles behind ODR. These legislative pieces include the Australian Guidelines for E-Commerce, ${ }^{58}$ the

53 T. Sourdin \& C. Liyanage, 'The Promise and Reality of Online Dispute Resolution in Australia', in M. S. Abdel Wahab, E. Katsh \& D. Rainey (Eds.), Online Dispute Resolution: Theory and Practice: A Treatise on Technology and Dispute Resolution, Eleven International Publishing, The Netherlands, 2012, pp. 483-509.

54 ADRAC, 'Online Dispute Resolution and ADR', ADRAC Toward Accord (16 September 2016), www. adrac.org.au/online-dispute-resolution, accessed 15 August 2021.

55 M. Coade, 'Compelling Case for Online Dispute Resolution' Lawyers Weekly (15 August 2016), www. lawyersweekly.com.au/news/19358-compelling-case-for-\%20online-dispute-resolu\%20on, accessed 15 August 2021.

56 Ibid.

57 Capic v. Ford Motor Company of Australia Limited (Adjournment) [2020] FCA 486.

58 The Treasury (Commonwealth of Australia), 'The Australian Guidelines for Electronic Commerce', The Treasury: Australian Government (17 March 2006, Canberra), http://archive.treasury.gov.au/ documents/1083/PDF/australianguidelines merce.pdf, accessed 15 August 2021. 
Consumer and Competition Act ${ }^{59}$ and the Electronic Transactions Act. ${ }^{60}$ The Australian Guidelines for E-Commerce aim to improve the public confidence surrounding e-commerce activities, by providing businesses with guidance regarding consumer protection in online transactions. The Consumer Competition Act is the main federal instrument for fair trading and commercial affairs. It governs the interrelationship between consumers and businesses from the business perspective, ensuring their compliance with legal conduct in commercial transactions. The Consumer Competition Act is examined in conjunction with the Electronic Transactions Act. The Electronic Transactions Act has been replicated at the state and territory levels. ${ }^{61}$ These Acts are based on two foundations: media neutrality and technology neutrality. ${ }^{62}$ Media neutrality requires equality of treatment irrespective of e-commerce or paper-based commerce, whereas technology neutrality fosters equity among the different forms of technology. ${ }^{63}$ These legislative changes have eased the adaptation to the online environment. Although they do not specify ODR, e-commerce mechanisms are very similar to the ideals behind ODR. These legislations can acclimatize to ODR needs.

Furthermore, the Australian Competition and Consumer Commission (ACCC) is the primary body that governs commercial disputes at the federal level. The ACCC is the most common point of access to the dispute resolution agencies. It provides the contact details of the federal and industry-specific ombudsmen, such as airlines, aged care, small business and telecommunications, among others. Since it is a point of contact for consumers to connect with official bodies, the ACCC has not implemented an ODR-based complaint mechanism. Still, it is worth noting as the predominant commercial dispute resolution database.

However, the distrust that impeded ODR from blossoming successfully continues to prevail in the ODR debates. Prior to the emergence of digital innovations, the Honourable Michael Kirby, former Justice of the High Court of Australia, alleged that AI programs for dispute resolution are 'ordinarily objectionable' 64 for the application of legal rules to human situations. This scepticism resonates with that of Chief Justice Allsop of the Federal Court of Australia. His Honour further elucidated that AI developments would not completely replace judges, as they would lack "discretional flexibility to respond to the constantly changing factual circum-

61 The State and Territory versions are: Electronic Transactions Act 2000 (NSW), Electronic Transactions Act 2000 (NT), Electronic Transactions Act 2000 (SA), Electronic Transactions Act 2000 (Tas), Electronic Transactions Act 2000 (Vic), Electronic Transactions Act 2001 (ACT), Electronic Transactions Act 2001 (Qld), Electronic Transactions Act 2011 (WA).

62 T. Sourdin \& C. Liyanage, 'The Promise and Reality of Online Dispute Resolution in Australia', in M. S. Abdel Wahab, E. Katsh \& D. Rainey (Eds.), Online Dispute Resolution: Theory and Practice: A Treatise on Technology and Dispute Resolution, Eleven International Publishing, The Netherlands, 2011, pp. 483-509.

63 M. Patterson, E-Commerce Law, 2001, p. 17.

64 M. Kirby, 'The Future of the Courts - Do They Have One?', Journal of Law, Information and Science, Vol. 9, No. 2, 1998, p. 141. 
stances in each and every case". ${ }^{65}$ Additionally, Clark and Hoyle constructed a narrative for the slow success of ODR in Australia. They suggested that there is much more "faith in and reliance on industry to lead the way and govern itself" ${ }^{66}$ Industrial relations in Australia are largely pluralistic, and view the state as an impartial and neutral entity. This may be a potential reason for the slow integration of public ODR platforms and government intervention within this sphere.

Nevertheless, the future looks bright for the expansion of ODR into the Australian commercial scope. ADRAC believes that for ODR to succeed, it relies on strong technology, such as Internet service and broadband capacity. The emergence of new technologies using cloud-based platforms will also mitigate the emergence of ODR on a domestic plane. ADRAC has also pondered the rebranding of ODR as dispute resolution in the cloud (DRIC) ${ }^{67}$ Furthermore, the National Small Business Tribunal (NSBT) currently operates as an independent dispute resolution body for small businesses. There are hopeful expectations for this ADR body to translate its procedures into the web-based environment in the future; ${ }^{68}$ the ideas published over a decade ago are yet to eventuate. The discussion around digitization for this tribunal boosts the confidence of other federal entities to transcend the traditional scope of ADR and immerse themselves in the ODR landscape. Consequently, there may also exist a possibility of a web portal conducting conciliation services through the Australian Government website. ${ }^{69}$

The ODR scope is limitless in Australia; the opportunities and benefits are boundless with the relevant adaptations and developments to the current models. ADRAC notes the lack of accountability and regulatory frameworks at the domestic level, ${ }^{70}$ but rectifies this loophole by acknowledging that Australia can adapt global standards into its local policies and guidelines.

\section{Limitations}

ODR has been implemented to some extent in the major jurisdictions; however, the parameters for e-processes are blurred in the long term. The redistribution of adjudicative and resolution powers has been questioned for posing a series of concerns. The judicial spheres of the jurisdictions have alleged that they are concerned about falling into a 'spiral of irrelevance' ${ }^{71}$ as a result of digitization. The contention

65 J. Allsop, 'Technology and the Future of Courts', Federal Court of Australia (26 March 2019), www. fedcourt.gov.au/digital-law-library/judges-speeches/chief-justice-allsop/allsop-cj-20190326, accessed 16 August 2021.

66 E. Clark \& A. Hoyle, 'E-ADR: On-Line Dispute Resolution: Issues and Recent Developments', 2002, p. 8.

67 ADRAC, 'Online Dispute Resolution and ADR', ADRAC Toward Accord (16 September 2016), www. adrac.org.au/online-dispute-resolution, accessed 15 August 2021.

68 The Treasury (Commonwealth of Australia), 'Resolution of Small Business Disputes', The Treasury: Australian Government (May 2011, Canberra), https://treasury.gov.au/sites/default/files/2019-03/ SBDisputesOptionsPaper.pdf, accessed 25 August 2021.

69 Ibid.

70 ADRAC, 'Online Dispute Resolution and ADR', ADRAC Toward Accord (16 September 2016), www. adrac.org.au/online-dispute-resolution, accessed 15 August 2021.

71 www.colinrule.com/writing/future.pdf. 
with the use of ODR lies in the deregulation of judicial processes, and the decentralization of power stemming from the courts. If ODR usurps the dispute resolution proceedings, the courts will be faced with the dilemma of regaining the public confidence and trust, which has been tainted by the new technologies. On a similar note, it has also been argued that ADR, and more so ODR, lacks fairness, especially when involving unequal parties. Empirical evidence on the matter indicates that out-of-court processes lead to poorer outcomes for the weaker party. ${ }^{72}$

Another consideration is the challenge in resolving larger scale disputes over the Internet. ODR is beneficial for repetitive, small claims; yet, there has been little to no implementation for larger scale disputes, and with parties comprising corporations and states. The ulterior understanding gathered from current international perspectives is that technological assistance can be optimized when used for small claims. Other than the Beijing Internet Court, the general consensus is to target these claims before acknowledging the idea of large claims.

The final aspect to bear in mind when discussing ODR is from a contractual perspective. Although ODR is more accessible in nature due to the flexibility and convenience it offers, there are still issues surrounding consumer protection. Generally, when ordinary people and consumers enter into contracts, the legal jargon may cause confusion and distance the average consumer from reasonable accessibility to ODR. Similarly, ODR processes may create the same feeling of cynicism in the ordinary individuals, and ODR must then be accessible in such a way that allows for understanding by the objective person. Finally, another issue that arises is a contract with 'accept all' clauses. The approach by the general public to these clauses is to interpret them as a shortcut to reading them. These contracts are riddled with complexity, and if there is an alternative not to read them, the reasonable person will opt for the latter option. This is an obstacle that contract-based ODR disputes will have to overcome.

\section{Conclusion}

It is indisputable that digital innovation is only starting to shape the way we operate, and there are high expectations for the possibilities brought about by technology. In turn, the e-commerce sector has given ODR the necessary impetus to develop and to reform conventional dispute settlement procedures.

Nevertheless, the benefits of ODR must be weighed against the pitfalls of digital environments. Among many other insecurities arising from online processes, ODR poses the risk of data breaches, lack of confidentiality and insecure consumer protection. For ODR to gain the reputable position of traditional methods of dispute resolution, the parties involved must acclimatize to ODR. Once it is normalized in the legal discourse, and legal experts overcome the nuanced obstacles, ODR can be regarded with the same respect as ADR and litigation. For these reasons, ODR has the potential to be successful in the settlement of small claims, but may not always be suitable for more complex cases.

72 R. Delgado, 'The Unbearable Lightness of Alternative Dispute Resolution: Critical Thoughts on Fairness and Formality', SMU Law Review, Vol. 70, No. 3, 2019. 
The reliance on technology-based ODR may be the most suitable avenue for small-claims disputes, primarily in the $\mathrm{B} 2 \mathrm{C}$ and $\mathrm{C} 2 \mathrm{C}$ segments. However, for more complex and singular cases involving B2B, and potentially class actions related to $\mathrm{B} 2 \mathrm{C}$ disputes, the discretionary power of the courts will still be greatly needed. 